\title{
NARRATIVE SPACE ARCHITECTURE AND DIGITAL MEDIA
}

\author{
Thomas Duncan and Noel McCauley \\ Duncan McCauley, Studio for Architecture and Digital Media \\ Invalidenstr. 115, 10115, \\ D -10115, Berlin \\ Germany \\ td@duncanmccauley.com \\ http://www.duncanmccauley.com
}

\begin{abstract}
The paper illustrates Narrative Space in the context of our completed work in a former industrial site that has been converted into a brickworks museum. Located near Berlin it is the largest of its kind in Europe. Narrative Space is used to describe the synthesis of singular or multiple stories with a spatial experience, made perceptible to an audience through a narrative structure. The illustrated work consists of installations combining architecture and digital media, which create experiential storytelling environments.
\end{abstract}

\section{INTRODUCTION}

As architects and storytellers, our understanding of the individual's subjective perception of space and its associative qualities is the basis for our exploration into the narrative potential that space embodies. Furthermore, our interest in film and digital media with their narrative and spatial possibilities has lead us to enquire how they can be combined with architecture to create spatial storytelling environments.

In the brickworks, our task was to identify and present traces of industrial usage together with the social context in a manner that would enable visitors to connect emotionally with the location's multi-layered cultural heritage. The site spans a period of over one hundred years of German history and has seen significant change. The altering social structures have left visible traces - against the background of the brickmaking process, which has remained much the same.

The unique aspect of the project is the manner in which video, audio and light are combined with the architecture of the heritage site to create experiential narrative environments. Using digital media, we have opened visitors' perception of the space to make the industrial and social memory visible. The experiential understanding of the surroundings is augmented by the use of soundscapes and projected images. Illusions are created which enhance visitors' emotional connection to the otherwise static industrial environment.

The digital media transform the factory spaces into a site of memory in an authentic manner, a place for play and reflection. Interpretive digital media installations manipulate visitors' perception by provoking the senses and thereby enhancing the experience of the space. Visitors can activate audio and light so that the machines move in their perception. Thus the industrial heritage of the site begins to resonate. 
Films are shown not as isolated works but are bound to the spaces by their synchronisation with sound and light outside of the screen space. Museum visitors traverse the architecture and the media of the factory spaces simultaneously.

\section{NARRATIVE JOURNEY}

A path leads viewers along a parcours that enables them to read the brickworks as a historical document and to gain an insight into working life in the former East Germany. The journey through the spaces of the former brickworks follows a narrative structure along which interpretive installations are placed. Each installation is created as a part of a whole, analogous to different scenes in a film. Together, the scenes create a consistent story with a twofold narrative: the brick-making process and the social structure in which it took place.

The parcours begins with a short film, which acts as a threshold and immerses the visitor into the brick factory and its environment. The film has a traditional cinematic structure but is conceived specifically as an introduction to the journey and is an integral part of the experience of moving through the factory space.

Set in 1985, the plot revolves around a family in which both parents who work in the factory have to overcome a crisis in order to be eligible for the much-needed bonus. The young daughter saves the day. The story illustrates how working and private life were tightly interwoven in the former East Germany. The film transports the visitor into the period when the factory was still producing bricks, introducing fictional characters who worked there. Viewers traverse the spaces of the working brick factory and the domestic space of the workers' apartment. The memory of the characters in the film personalises visitors' connection to the disused brickworks. At the end of the film a door opens automatically and the visitor is invited into the historical spaces of the brickworks themselves. 


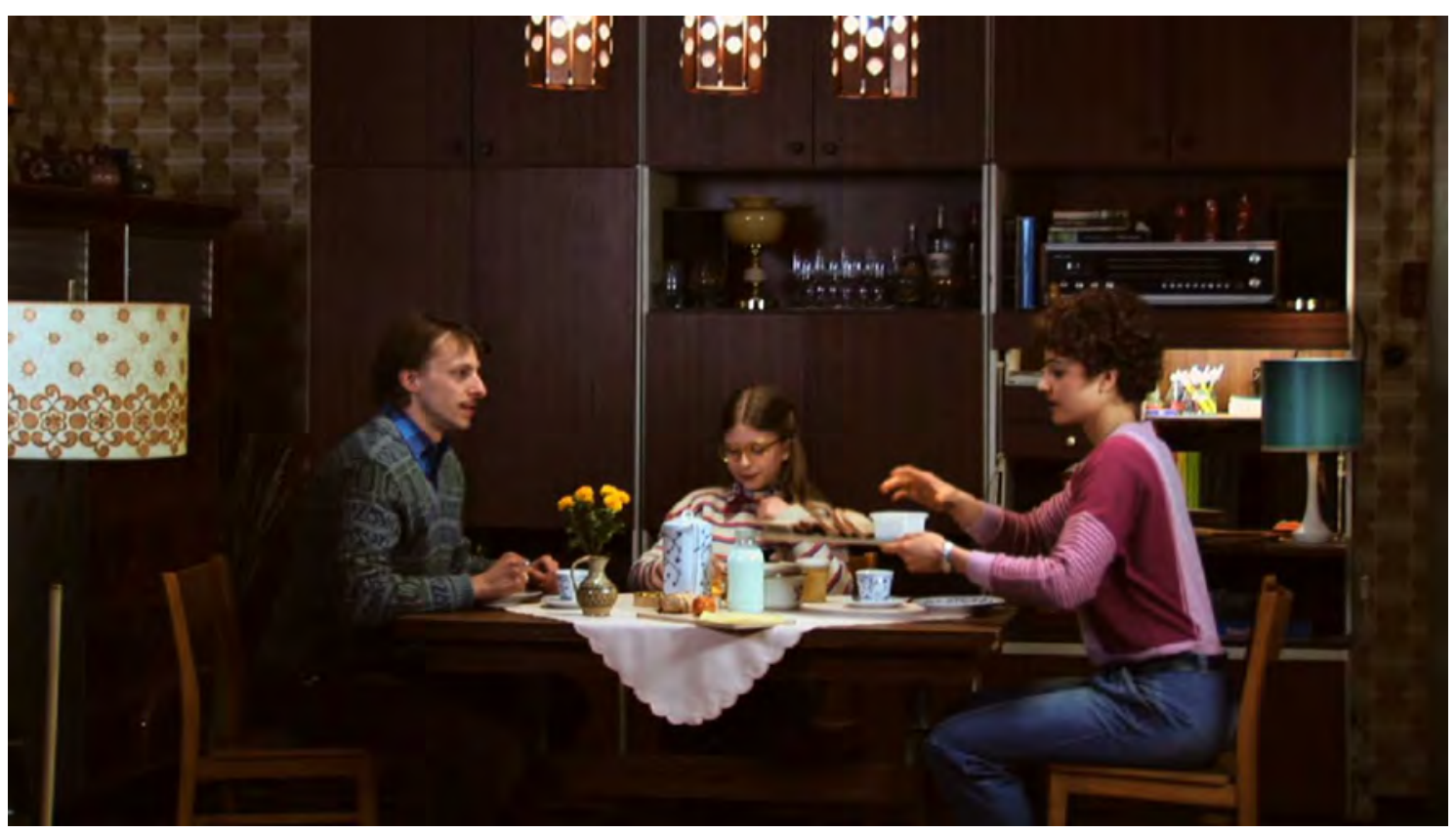

Figure 1. Still from the film Plansoll Duncan McCauley 2008, 10 Min.

\section{AUGMENTED SCREENSPACE - TALKING HEADS}

The aim of the talking heads is both to document the industrial process and reintroduce the presence of the workers at their former workplace, creating an emphatic connection between the subject and the viewers. Over 40 interviews were carried out with former brick workers. The 'talking heads' are vertical screens placed in modern exhibition elements. Integrated media-stations are created, where the films become part of the environment with up to 18 audio channels placed within each factory space. An architecture of sound, together with lighting, is synchronised to the film. The audio animates the workers' descriptions of the brick-making process and is accentuated by lighting illuminating the source of the sound and the movement of the clay or bricks.

The film content tells the story of the room, creating a narrative spatial experience together with the soundscape. The workers were interviewed at their former place of work within the factory. The positioning of the screens at these points enhances the relationship of the viewer with the subject. A transfer of experience takes place, connecting viewers emotionally with the site. 


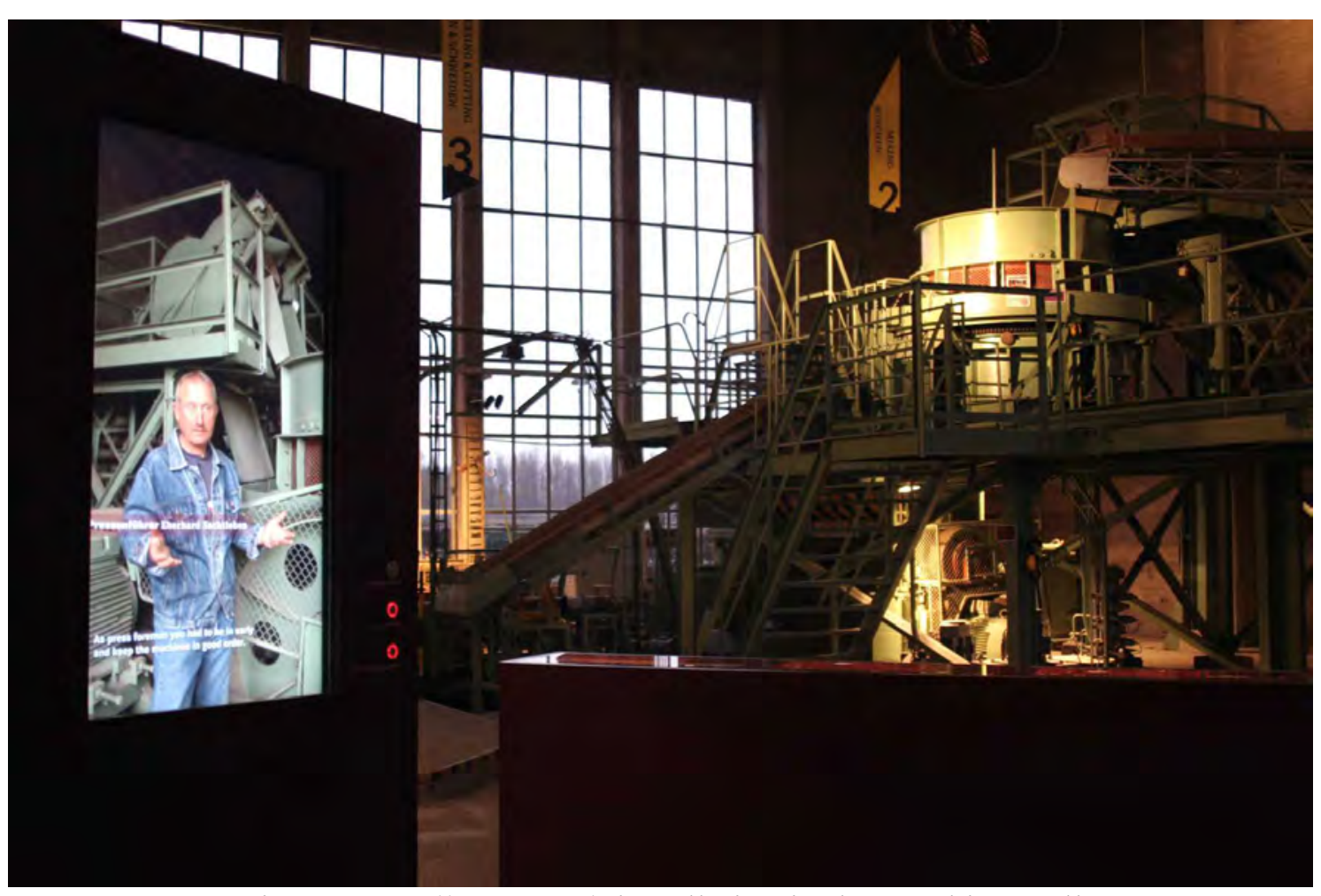

Figure 2. Talking Heads installation in the Machine Hall

The creation of an audio environment enables visitors to empathise with the place where bricks were once made. Loudspeakers are positioned specifically to create the sound of the working factory, e.g. along the train tracks, inside the conveyor belt mechanism, or in the clay mixing machine. The former factory resonates with its industrial and cultural heritage. The soundscapes have a strong reference to the brick factory but also respond to the site as a contemporary museum, projecting an intuitive collage of memories onto the space. The interviews, documenting the cultural heritage of the brick-making process in the GDR, have now become an important part of the museum's archive. 


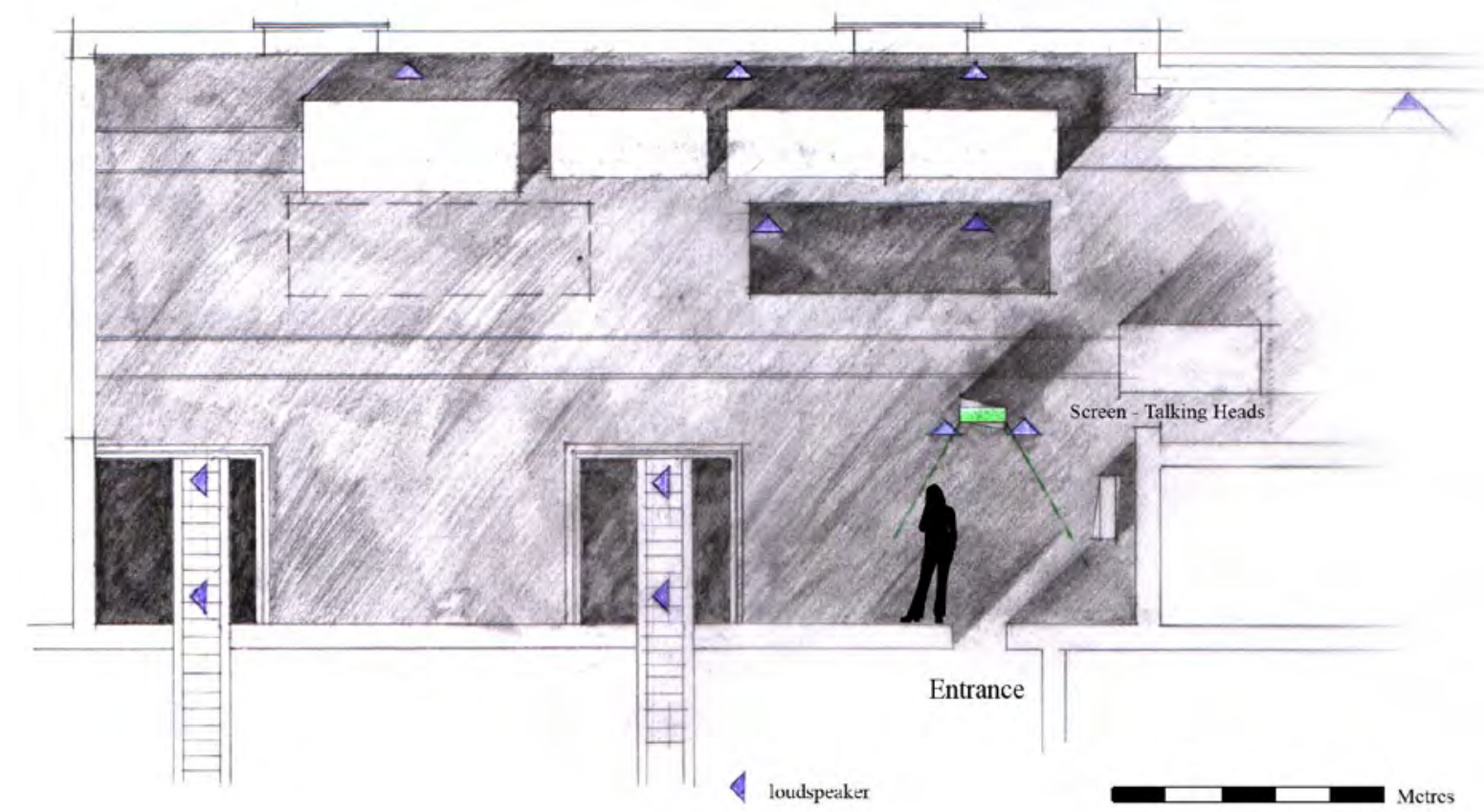

Figure 3. Talking Heads. The floorplan shows the positioning of the loudspeakers in the machinery in relationship to the screen.

\section{AUGMENTED PHYSICAL SPACE - THE TROLLEY SHIFT}

Using large-scale high definition digital projection, we are able to reinterpret and represent space within the factory. By adding a moving object to the projected image we have created an illusion where the boundaries of the physical space and the implied projected space intertwine. The installation is an illusion that works with depth of field and site lines. Though it works most accurately from one position in the room when the site lines between the projected image in the foreground and the architecture and the moving trolley in the background line up, exact positioning is not necessary for the effects of the installation to be appreciated, due to its experiential strength.

Behind the screen, a motorised trolley moves along a $15 \mathrm{~m}$ length of track. In the foreground a wall in front of the path of the trolley is projected with the image of the background; the wall is essentially projected away, made invisible by the continuum of the background image. As the real trolley passes behind the wall, a projected trolley appears, being pushed by a worker. The real trolley reappears behind the $2.5 \mathrm{~m}$ wide projection screen and the worker disappears but the trolley continues to move. The trolley returns, and the projected worker reappears pushing the trolley back in the opposite direction. The moving trolley is a continuum in both the physical space and the digital projection, and so connects the two realms. The presence of the real trolley draws the content of the projection into the physical space, enhancing the connection of the viewer and the projected figure of a female worker. 


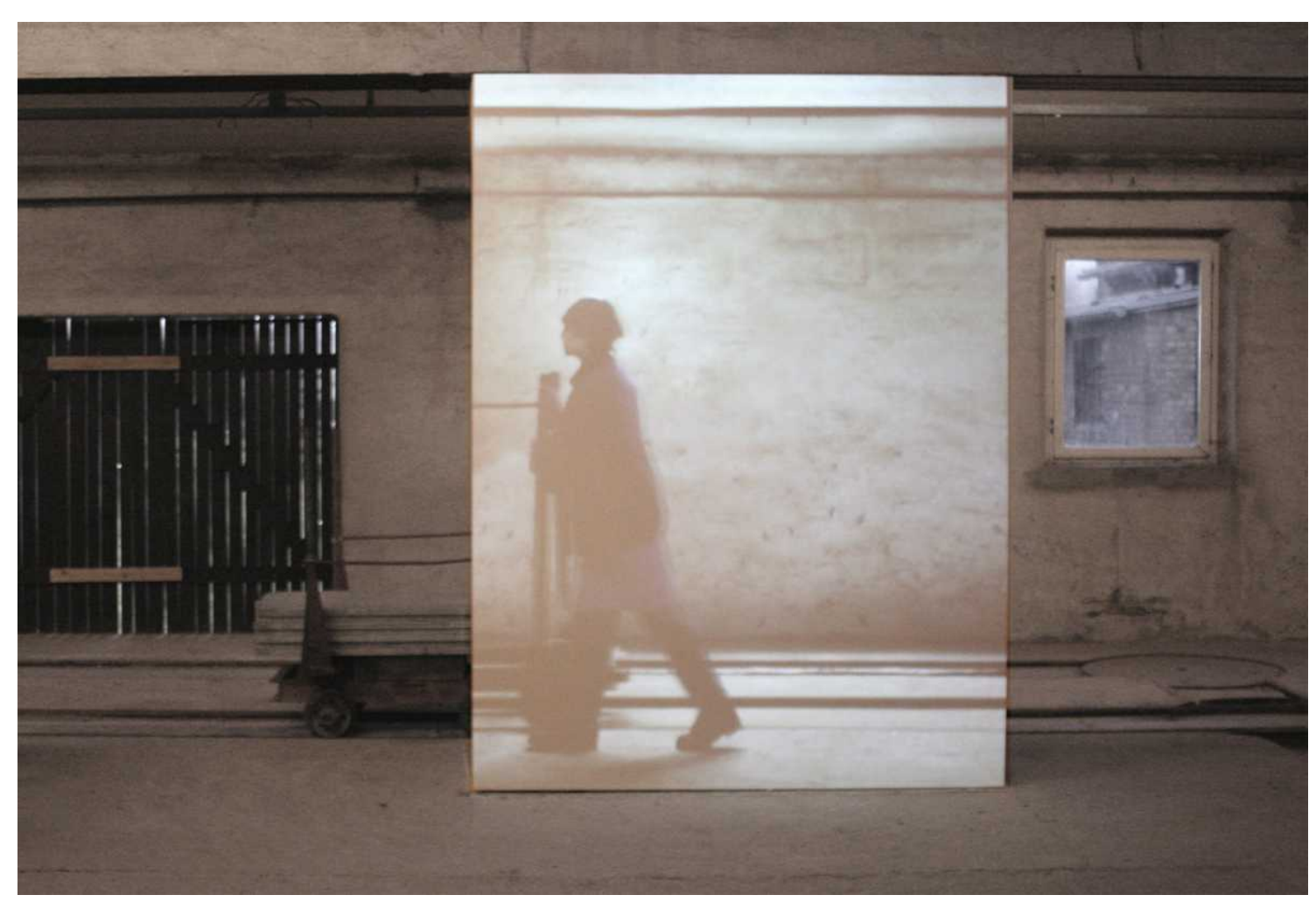

Figure 4. The Trolley Shift. The photograph shows the projected trolley and the real trolley.

The illusionary effect is that the viewer expects the female worker to walk off screen and continue to push the real trolley. The real moving trolley increases the presence of the digital image in the space to such an extent that the viewer is momentarily surprised by the fact that the projected image of the female worker cannot cross the boundary into real space. The illusionary factory worker is also the main character in the short film at the start of the journey; her reappearance acts as a narrative echo.

The "talking heads" connect the visitor to the place through story telling and aural spatial interaction; the trolley installation draws visitors into the illusion of a person at work by stimulating their experiential and spatial perception. 


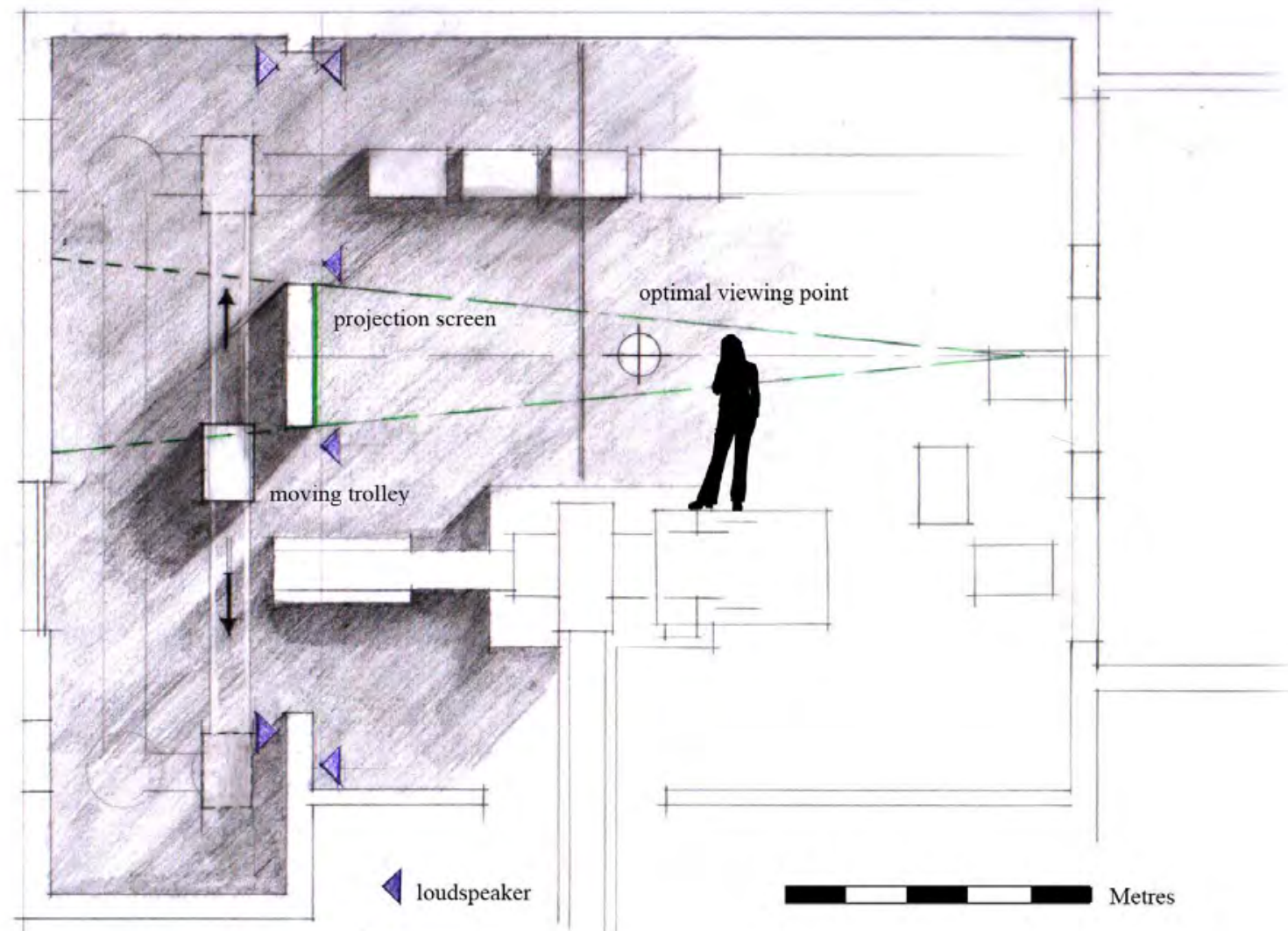

Figure 5. The Trolley Shift. A floorplan showing the position of the viewer in relationship to the trolley and the projection screen.

\section{THE CIRCULAR KILN - A HAPTIC MEDIA INSTALLATION}

Synchronised lighting illustrates the sequential industrial process on the journey through the factory spaces. Only two colours of light are used throughout the project. White light traces the path of the clay and un-burnt bricks and red light is used to denote heat. At the last stage of the parcours within the circular Hoffmann kiln, visitors are invited to pick up a glowing white brick and take it with them on their journey through the $80 \mathrm{~m}$ long firing tunnel. Ultrasonic sound waves trigger preset colour settings in the programmed LED (rgb) lights in the translucent brick depending on the visitors position. By picking up a brick and walking through the oval kiln, visitors become simultaneously viewers and performers; as they proceed with the light-brick around the tunnel the brick changes colour. The change in colour relates to the different temperatures within the kiln, illuminating the firing tunnel in shades between white and deep red. Visitors experience the changing temperature of the kiln in a haptic manner. 


\section{EVA 2009 London Conference 6-8 July}

Thomas Duncan and Noel McCauley

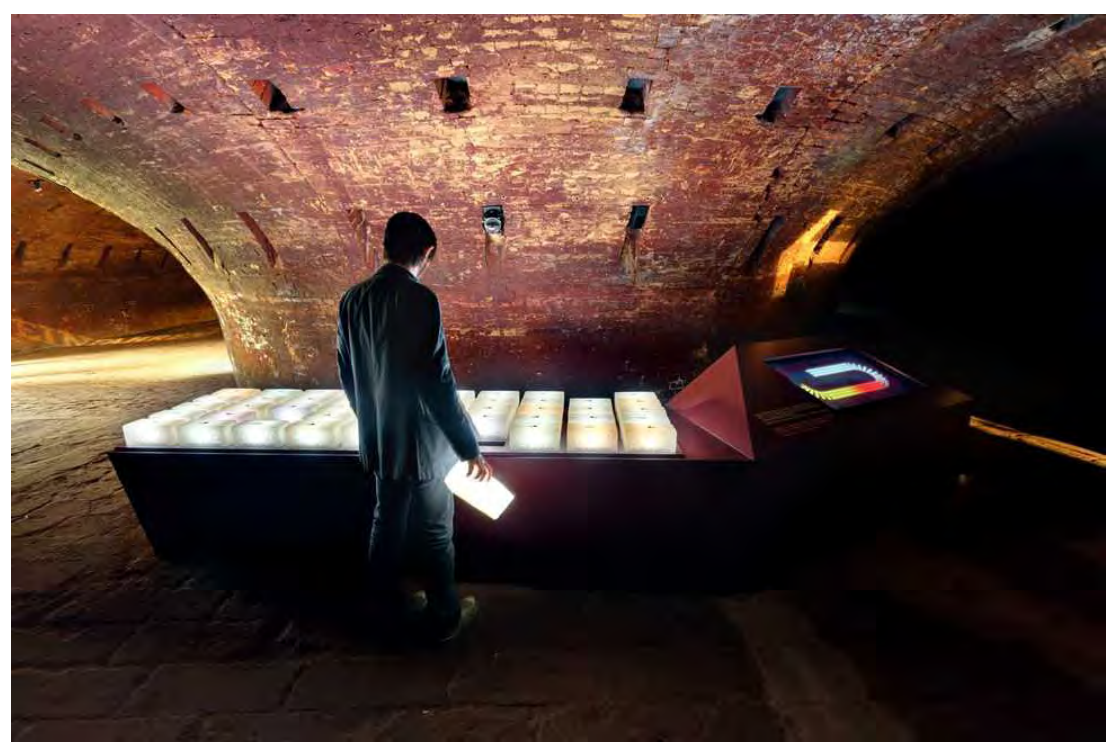

Figure 6. A visitor taking a glowing white brick inside the firing tunnel of the circular kiln.

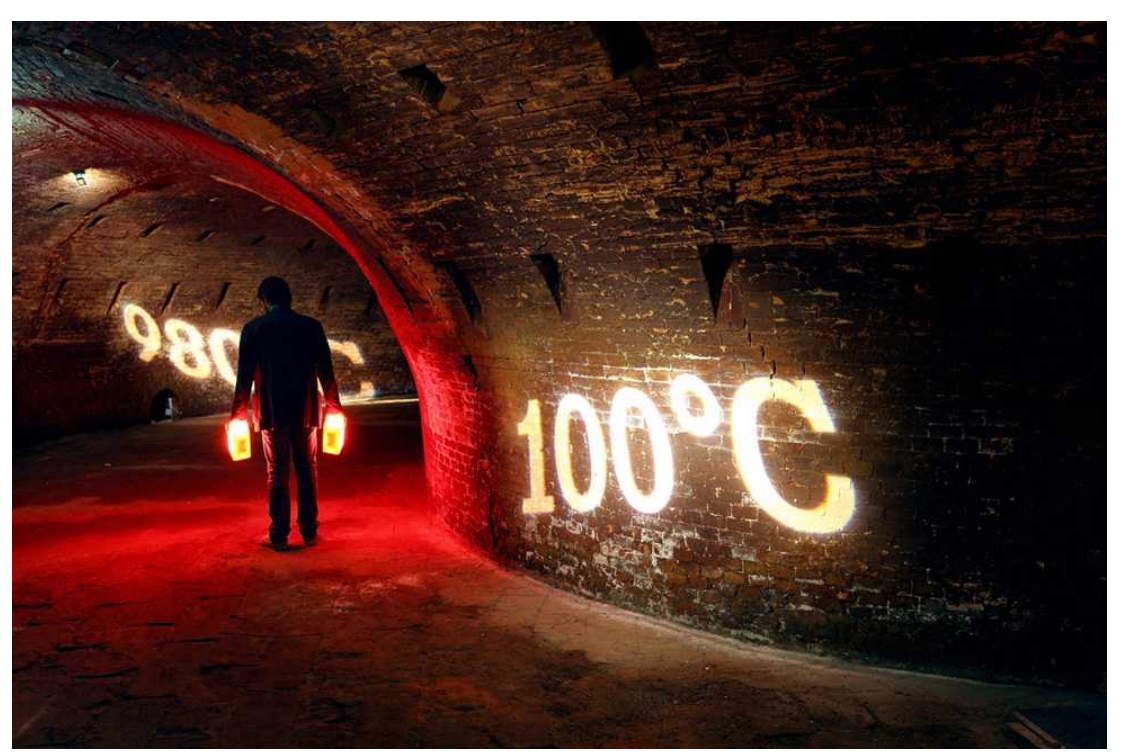

Figure 7. The bricks change colour as the visitor proceeds through the firing tunnel.

The 32-channel soundscape recreates the circular movement of air and fire as an architecture of sound. The loudspeakers are placed out of sight within the firing-tunnel vault, randomly spaced so that visitors cannot locate the source of the sounds. The soundscape within the kiln is in two sequences, each about 4 minutes long: a firing process and reflection. The firing process re-enacts the activities within the kiln: green bricks are stacked, air moves, coal is tipped and the fire ignites, the fired bricks cool and the bricks are transported out of the kiln. Visitors move through different dedicated sound areas. 
The reflection sequence is a response to the architecture of the kiln and the circular movement of the fire. It is a composition, which is both musical and spatial. The music underscores the associative qualities of the implied space of the kiln, similarly to a film score. It creates a dynamic tension and moves in space in relation to the visitor. The chord structure shifts harmonically, repeating as it circulates. Within the environment of a dramatic soundscape the changing colour of the brick in the visitors' hands is a haptic media experience which tells the story of the kiln.

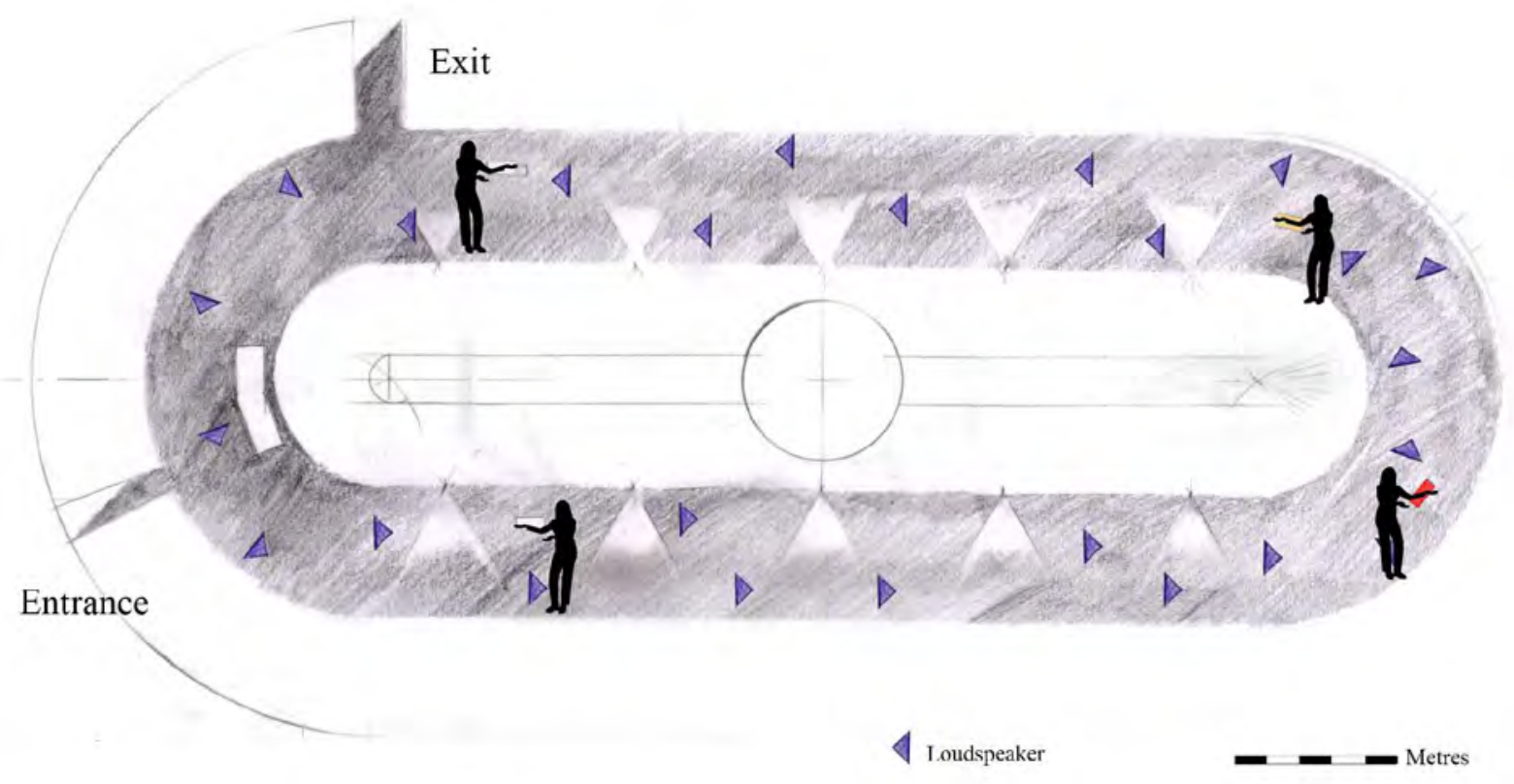

Figure 8. The Circular Kiln. 32 discreet audio channels are placed inside the firing tunnel. The visitor carries an interactive light-brick around the kiln.

\section{CONCLUSION.}

We live in worlds in which the material and the mental, the experienced, remembered, and imagined completely fuse with each other [1].

To affect us emotionally, a place has to speak to us through our intuitive experience. We have illustrated how the synthesis of architecture and digital media within a narrative structure can create a storytelling environment and establish an emotional contact between the viewer and the place. Executed in an authentic and consistent manner, the narration is finely choreographed, holding visitors' attention throughout the journey and making didactic information relating to the site accessible.

Given the history of the installations which gave rise to film it is only appropriate that the cinema and the museum should renew their convergence in ways that foster greater hybridisation [2]. 
The unique combination of digital media and architecture at the brickworks has established the museum within the cultural landscape of Germany. Since its opening in March 2009, the resonance on a regional and national level has been overwhelmingly positive. Our research in the field of digital media and architecture continues with further projects for museums and cultural institutions.

\section{References}

[1] PALASMAA, J. Encounters, architectural assays. Finland : Rackennustieto Oy, 2005.

[2] BRUNO, G. Atlas of emotion, journeys in art, architecture, and film. New York : Verso, 2002. 